\title{
Alejandrino Fernández Barreiro: ADIÓS A UN GRAN UNIVERSITARIO
}

Me lo dice con delicadeza mi fraternal amigo y colega Antonio Fernández de Buján sabiendo que me va a doler: "Ha muerto Alejandrino" y me transmite tan triste nueva con un tono de voz que pone de manifiesto con claridad meridiana los fortísimos vínculos afectivos que los unían. Nunca se sabe bien qué pasa por nuestra mente bañada siempre por la sensibilidad de la que nunca podemos desprendernos, cuando oímos como un golpe sordo la noticia. La muerte es una cita irremplazable para el ser humano pero es -en terminología romanista- un dies certus an incertus quando; con todo, su edad y su jovial apariencia física permitían presumir que la llamada de la Parca podía demorarse mucho. Este mismo año, en febrero, la Facultad de Derecho de La Coruña, su Facultad, le confirió el título de profesor ad honorem como premio a los inestimables servicios que le prestó como docente, investigador y gestor académico. Su lección jubilar ante lo más granado de la comunidad universitaria y del mundo del foro constituyó un cabal testimonio de su prodigiosa inteligencia, su sentido del deber y su vocación científica. Nada hacía prever, pues, un tan rápido fatal desenlace. La intervención quirúrgica a la que se sometió a finales de mayo fue el punto de salida hacia su muerte, según me transmitía puntualmente su filial -en el pleno sentido del vocablo- Julio García Camiñas. El punto de llegada se produjo unos pocos meses después. Todas las noticias de muerte, de aniquilación, de pérdida, tienen algo terrible, incomprensible, cuando esas noticias no vienen del horror generalizado con que nos inundan inevitablemente los medios de comunicación, sino que se te acercan, llaman a la memoria concreta de la vida y te dicen que algo próximo, inmediato, ha causado un desgarro, una herida en lo más profundo, en aquello que -junto al lenguaje- nos hace seres humanos: la amistad.

Confieso que, por este desgarro, me cuesta trabajo escribir las presentes líneas ya que compartí con Alejandrino Fernández Barreiro muchas peripecias humanas 
y científicas, desde nuestra común convivencia como residentes en el Colegio Mayor "La Estila" de Santiago de Compostela, hasta el acto trascendental en la vida académica de todo universitario vocacional: la tesis doctoral. La mía fue la primera tesis que dirigió y a él debo mi iniciación, con las firmes bases que me construyó, en los duros caminos de la investigación romanista: mis trabajos aurorales serios se los debo a él. Siempre he sido acompañante fiel de sus actividades profesionales, a la par que admirador sin tacha de sus virtudes cívicas. En efecto, Alejandrino Fernández Barreiro era un señor, un catedrático al viejo estilo, de esa gente con un nivel de educación y calidad humana tan poco frecuente en la actualidad. Tenía una displicencia muy positiva respecto a las exquisiteces dogmáticas.

La idea de pensar que un hombre de su envergadura biográfica y moral haya desaparecido resulta en estos momentos inaceptable. Alejandrino no hubiera debido dejarnos y lo sostengo no por razones sentimentales, que las hay y muchas, sino porque creo que en la Universidad española alguien como él hace mucha falta. Por muchos motivos. Para recordar algunas de las cualidades que acabo de mencionar y muchas otras que poseía, queda su obra intelectual y científica. Aquellos que me leen van a tener la bondad de relevarme de la obligación de exponer minuciosamente los sucesivos pasos de la larga y fecunda carrera académica del Prof. Fernández Barreiro. Sería en exceso prolijo para una inveterada costumbre universitaria cuya majestuosa sobriedad impone el deber de ser breve. Las obras del ilustre jurista hablan por sí. Para hablar pues de Alejandrino Fernández Barreiro, el hombre, solamente dos pinceladas que esbocen su figura.

Ourensano de nacimiento, tras cursar la carrera de derecho en la Universidad de Santiago de Compostela con brillantísimas calificaciones, se doctoró en la Universidad de Navarra con una tesis doctoral dirigida por el profesor Álvaro d'Ors que ha sido unánimemente elogiada por la romanística europea. Tras un período de estancia en Roma, en donde trabaja con los Profesores Pugliese y Volterra, y París, con el Prof. Gaudemet, se reincorporó a la Universidad de Santiago en donde desempeñó funciones docentes y continuó sus trabajos de investigación. En 1973 fue nombrado profesor agregado de derecho romano en la Facultad de Derecho de la Universidad de Granada, tras haber sido propuesto por unanimidad para la primera plaza por el Tribunal del concurso-oposición. Fue director del Centro Asociado de la UNED de Pontevedra, entonces el único de todo el norte de España, a cuya consolidación definitiva contribuyó con entusiasmo; en 1974 y en virtud del pertinente concurso de acceso, fue promovido al puesto de catedrático de la Universidad de Santiago de Compostela, en la que permaneció ininterrumpidamente hasta su traslado a la Universidad de La Coruña en 1987, de la que fue su primer secretario general. Posteriormente fue decano, con reelección, de la Facultad de Derecho y formó parte con el autor de estas líneas, de la Comisión Permanente de la Asamblea de Decanos de Facultades de Derecho de la Unión Europea. En este peregrinaje por distintas universidades, Alejandrino Fernández Barreiro fue, sobre todo, un sobresaliente docente y en ellas dejó la impronta de su gran magisterio científico y humano en generaciones de juristas.

El compromiso del profesor Fernández Barreiro con su tierra, sus instituciones y su derecho queda más que patente. Diputado al Parlamento Autonómico, 
conselleiro de Educación y Cultura en dos gobiernos, su preocupación por las peculiaridades jurídicas propias fue justamente reconocida con su nombramiento como académico de número de la Real Academia Gallega de Jurisprudencia y Legislación ${ }^{1}$.

Por último, en el terreno de la convivencia universitaria, profesores y alumnos siempre encontraron en él a una persona abierta, dialogante y comprensiva. Sumido en la vida de la Facultad y con una visión auténtica de la misión orteguiana de la Universidad, se preocupó siempre de los problemas de la institución, fomentó las vocaciones universitarias e, incluso, como acaeció hasta que, administrativamente, fue jubilado, desempeñó diversos cargos académicos, no hurtándose, como sería lo más fácil, al pago del tributo de servicio que todos tenemos con nuestra alma mater.

Pero el Prof. Fernández Barreiro excede evidentemente a los romanistas al uso. Originariamente fue un romanista con toda la profundidad histórica del calificativo, pero también un excelente comparatista y un magnífico iushistoriador $^{2}$; ha sido, pues, un romanista de múltiples inquietudes; porque también en el derecho ocurre lo que acontece en los idiomas, que el que solamente conoce una lengua ni siquiera esa lengua conoce. Y como no podía ser menos, dado el carácter central que el derecho romano ha tenido y sigue teniendo en el campo jurídico, fue extendiendo el Dr. Alejandrino Fernández Barreiro sus investigaciones a las fuentes del derecho, a la metodología jurídica, para entrar de lleno en el derecho comparado y en el análisis de la tradición romanística hasta nuestros días, siempre con la finura, precisión y profundidad que adornan a los auténticos juristas.

Mi condición discipular determina que omita voluntariamente hablar en términos analíticos -ya que una exposición en esta sede sobre la obra científica del profesor Fernández Barreiro sería totalmente esquemática e inadecuada- pero, con todo, cumple calificarla de obra vastísima y ecléctica que afronta magistralmente los temas del derecho sustancial y procesal; escrita toda ella con una pulcritud de estilo que refleja su probidad intelectual, un estilo forjado lentamente, nacido de la frecuente compañía de los clásicos. Podrían citarse muchas páginas que revelan este modus procedendi desgraciadamente infrecuente en los usos académicos.

La expresión de la verdadera inteligencia suele ser una exhibición en el juicio que se basta por sí misma, pero cuando va acompañada de una cultura sólida,

${ }^{1}$ Estos datos de la semblanza biográfica del Prof. Fernández Barreiro están tomados de mi "Presentación” a FernÁNDEZ BARREIRO, A., Estudios de derecho procesal civil romano, recopilados y publicados por la Universidad de La Coruña en 1999, con motivo de sus bodas de plata con la cátedra, pp. 11-15.

${ }^{2}$ No podemos dejar de transcribir lo que el ilustre catedrático de la Sorbona, Prof. Gaudemet señala de la obra del Prof. Fernández Barreiro, Los estudios de derecho romano en Francia después del Código de Napoleón (Roma - Madrid, 1970) : “On pourrait s'étonner du peu d'intérêt porté par les histoires du droit français aux vicissitudes de l'étude et de l'enseignement du droit romain dans leur pays depuis 150 ans. Et l'on doit de se réjouir de constater que cette lacune est heureusement comblée par le travail d'un jeune historien espagnol [...] ; son études s'insère dans une réflexion largue, qu'alimente l'histoire comme le droit comparé, qui tient les rapides mutations des ordres juridiques contemporains pour l'expression de profonds changements sociaux, qui croit que l'indéniable utilité de toute technique n'implique pas l'abandon de disciplines fondamentales" [en RHDFE., 49 (1971), pp. 641 ss.]. 
como era el caso del Prof. Fernández Barreiro, cuenta con una hoja de ruta para hacerla eficaz que resulta impagable. Y la solidez cultural de Alejandrino Fernández Barreiro venía no sólo de la extraordinaria formación jurídica que lo hizo uno de los grandes profesionales del derecho en nuestro país, sino de la riqueza de sus intereses culturales, ya fueran musicales, literarios o cinematográficos, que expresaban la vitalidad de este querido amigo y maestro.

Sin embargo, no pretenden estas líneas poner de manifiesto un perfil acabado de las realizaciones y de la personalidad de Alejandrino Fernández Barreiro; tan solo quieren sugerir la entidad y la proyección de una actividad casi desbordante y de una muy decantada manera de ser y de hacer. La impronta que el Dr. Fernández Barreiro a lo largo de su dilatado camino profesional ya ha sido, siquiera esquemáticamente, expuesta. Mas cumple concluir esta laudatio con una serie de consideraciones que constituiría una magna preterición, so pretexto de su academicismo, no mencionarlas: Ante todo, dejar constancia de su excepcional sentido del humor, que suavizaba los enfrentamientos, pero que, sobre todo, humanizaba las relaciones: Alejandrino Fernández Barreiro era profundamente humano. Su desinhibición, sin solemnidades ni complejos, siempre ejercida con rigor, todo lo independiente que quiso: un español raro. El que esto escribe siempre ha dicho públicamente que él tenía un derecho más que merecido al título de "lord Alejandrino of Leiro". Ahora recuerdo su cena jubilar en La Coruña, en el pasado febrero y su afabilidad como una de las señas de la identidad galaica en la que tanto se reconoció sin aldeanismos, y me parece mentira que se nos haya acabado el privilegio de tenerlo con nosotros y tratarle. Siempre tendré presente aquella fina sonrisa y aquel punto de ironía que le permitía relativizar lo más dogmático para acercarse, relajadamente, al debate amable entre contendientes muy opuestos. Es hoy un ejemplo algo insólito en nuestro panorama universitario pero seguramente porque pocos podrían aportar a este tipo de debates el contenido, la fundamentación y el valor del alto ejemplo personal de Alejandrino Fernández Barreiro. Nuestro añorado profesor hace honor a su nombre de pila: es un ciudadano alejandrino polígloto y cosmopolita, abierto al diálogo y al pacto, sensato y templado. Mas todo ello, no hubiera sido posible sin la inestimable contribución de su esposa omnis vitae Lutgarda García-Boente quien no sólo formó con él un hogar ejemplar, sino que creó el ambiente vital necesario para que una obra científica de esta magnitud produjese tan próvidos frutos. Hasta siempre, maestro y amigo.

Luis RODRÍGUEZ ENNES Universidad de Vigo 